\title{
O tabu da educação sexual: gênese e perpetuação dos preconceitos na infância*
}

\author{
Mariana Inés Garbarino**
}

\begin{abstract}
Resumo
Durante duas décadas, o eixo "orientação sexual" fez parte do currículo escolar brasileiro como tema transversal. Não obstante, apesar da proliferação de pesquisas sobre esse tema, poucos são os estudos que mapeiem o atual papel dos contextos sociais (família, escola, mídia, etc) na perspectiva da psicogênese do conhecimento sexual. Nessa ótica, o presente artigo discorre acerca das condições de produção dos preconceitos sexistas na interface entre aspectos socioculturais e operadores conceituais da psicologia do desenvolvimento infantil. Tendo-se constatado que na literatura prevalecem as análises das representações de pais e professores, escolheu-se escutar as próprias crianças. O estudo visa mapear se as representações sobre identidade de gênero que foram detectadas em estudos empíricos realizados nas décadas de 1960 e 1980, nos Estados Unidos e na França, são também observadas no contexto atual brasileiro. Para isso, foram entrevistadas 80 crianças de 4 a 9 anos, indagando suas ideias acerca da diferença sexual e de gênero. Os resultados permitiram observar parcialmente alguns traços das pesquisas referenciadas, podendo-se inferir o movimento representativo de uma progressão que vai dos estereótipos de gênero à consideração da anatomia sexual. Em comparação ao protagonismo da família como educadora sexual, a escola foi pouco mencionada como transmissora do conhecimento, o que demonstra a necessidade de indagar os impactos da circulação do dito e não-dito sobre sexualidade nessa instituição. Concluiu-se salientando a fecundidade da análise dialética dos aspectos sociais e cognitivos do desenvolvimento no estudo dos preconceitos sexuais na infância.
\end{abstract}

Palauras-chave: Educação sexual, Identidade de gênero, Psicogênese, Desenvolvimento infantil, Preconceitos.

\footnotetext{
* Recebido em 12 de agosto de 2019, aceito em 30 de agosto de 2021.

** Pesquisadora do Instituto de Psicologia, Universidade de São Paulo (USP), São Paulo, SP, Brasil. marianaigarbarino@gmail.com/ https://orcid.org/0000-0003-3013-909X
} 
The taboo of sex education: Genesis and perpetuation of prejudice in childhood

\begin{abstract}
For two decades, "sexual orientation" was a transversal theme in the Brazilian school curriculum. Nevertheless, despite the proliferation of research on this topic, there are few studies that map the current role of social contexts (family, school, media, etc.) to consider the psychogenesis of sexual knowledge. In this light, this article discusses the conditions of the production of sexist prejudices at the interface between socio-cultural aspects and conceptual operators of the psychology of child development. Having found that the analysis of parents and teachers' representations is predominant in the literature, we chose to listen to the children themselves. The study sought to determine whether representations about gender identity that were detected in empirical studies from the 1960s and 1980s in the United States and France are also observed in the current Brazilian context. To do so, 80 children, from 4 to 9 years old were interviewed apropos their ideas concerning sexual and gender difference. The results allowed partially observing some traits identified in the studies examined, and a movement can be inferred that represents a progression from gender stereotypes to the consideration of sexual anatomy. In comparison to the role of the family as a sex educator, the school was little mentioned as a transmitter of knowledge, which demonstrates the need to investigate the impacts of the circulation of the said and unsaid about sexuality in this institution. The conclusion emphasizes the fruitfulness of the dialectical analysis of social and cognitive aspects of development in the study of sexual prejudices in childhood.
\end{abstract}

Keywords: Sexual Education, Gender Identity, Psicogenesis, Child Development, Prejudices. 
No Brasil, o eixo "orientação sexual" foi incorporado em 1997 nos Parâmetros Curriculares Nacionais (PCNs) desde o Ciclo I do Ensino Fundamental. A partir da sua inserção no currículo e em projetos de formação de professores, o sexismo e a diversidade de identidades de gênero deveriam ser abordados em seu estatuto curricular de "tema transversal" (Altmann, 2001; Vianna, 2012; Madureira; Branco, 2015). Contudo, recentemente o tema foi suprimido na nova Base Nacional Comum Curricular (BNCC, Brasil, 2019). O evento torna-se especialmente preocupante considerando-se que os dados sobre situações de violência relacionadas com preconceitos sexuais continuam sendo alarmantes: a Pesquisa Nacional sobre o Ambiente Educacional no Brasil (2016) verificou que $73 \%$ dos estudantes LGBTQIA+ já foram atacados verbalmente e $36 \%$ já foram agredidos fisicamente na escola (Tokarnia, 2016).

Ao longo dos anos, várias foram as tentativas de erradicar essas práticas no contexto escolar, seja a partir da legislação, seja a partir da introdução de práticas pedagógicas e material didático. Em 2011, foi proposta no Senado a elaboração e distribuição de um "kit contra homofobia" e, na mesma época, foi apresentado um projeto de lei para criminalizar o preconceito contra homossexuais, transexuais e transgêneros (Balieiro, 2018).

A orientação sexual como tema transversal no currículo escolar torna-se impostergável $e$ pertinente em função das novas configurações familiares e dos direitos da população LGBTQIA+. No cenário da América Latina, a Argentina se tornou, em 2010, o primeiro país a legalizar o casamento homossexual e a reconhecer os direitos de homoparentalidade. Já no Brasil, ainda que em 2011 tenha sido legalizada a união homoafetiva, a possibilidade de adoção homoparental vem provocando intensos debates. No polo oposto dessas iniciativas, e também no Brasil, o projeto de lei de "cura gay" para o tratamento psicológico da homossexualidade (contra a qual lutaram várias instituições, dentre elas o Conselho Federal de Psicologia), ilustrou a atualidade do fenômeno de patologização e biologização da homossexualidade, paradigmas do histórico reducionismo da sexualidade humana (Venancio; Belmonte, 2017).

Nesse sentido, as pesquisas sobre educação sexual no âmbito escolar vêm discutindo os aspectos sócio-históricos do sexismo, focando notadamente os preconceitos de professores e pais, os estereótipos fomentados pelas escolas, a vulgarização da sexualidade humana na mídia e a ausência ou distorções de explicações sobre as diferenças sexuais, os papéis de gênero e a reprodução humana (Guimarães, 1995; Camargo; Ribeiro, 1999; Nunes; Silva, 2000; Figueiró, 2009; Madureira; Branco, 2015).

No que diz respeito às representações e discursos dos adultos acerca da sexualidade, prevalece o estudo das crenças de professores e pais (Altmann, 2009; Reis; Maia, 2009; Madureira; Branco, 2015). Na instituição escolar, as posições diversas dos professores funcionam ou como prolongamento da família e reforço de seus valores, ou como meio de abertura de horizontes para a criança na linha de sua emancipação, ou como agente moralizador (Guimarães, 1995; Moizés; Bueno, 2010).

Em relação ao sexismo presente nos livros didáticos, a associação da mulher às tarefas domésticas e do homem ao "provedor" tem diminuído (Moreno, 1999), o que pode ser explicado, em parte, como um reflexo de mudanças no âmbito laboral: ainda que as mulheres sigam dedicando mais tempo aos serviços domésticos do que os homens, observa-se um deslocamento das fronteiras do masculino e do feminino e significativas modificações nas modalidades dessa divisão (Hirata, 2002).

No que se refere à coeducação comunidade-escola, diversas pesquisas brasileiras mostram que, por um lado, é frequente a ausência de convocatória da participação dos familiares para abordar sexualidade, mas, por outro, observa-se que muitas famílias acreditam que a escola possui o saber "certo" e, portanto, abstêm-se de explicar às crianças questões em torno do tema (Reis; Maia, 2009; Moizés; Bueno, 2010). Os autores dos estudos inferiram que haveria um sentimento de incompetência ou incapacidade das famílias para se posicionar como possuidoras de conhecimento, e que a delegação dessa responsabilidade responderia ao desejo de resguardar-se do encontro com a própria intimidade sexual (Reis; Maia, 2009).

Historicamente, família e escola, contextos prevalentes na infância, constituíram dispositivos de poder e controle permeados pelas chamadas "políticas sexuais", que, por diferentes meios, 
reduzem a sexualidade "à sua função reprodutiva, à sua forma heterossexual $e$ adulta $e$ à sua legitimidade matrimonial" (Foucault, 2010:114). Conforme Foucault (2010), a partir do século XVIII, "a pedagogização do sexo da criança" foi um aparelho estratégico de saber e poder sobre o sexo, cujo grande expoente foi a "guerra contra o onanismo".

Todavia, na atualidade, essa mesma lógica de controle se apresenta como "a outra face da moeda". Sob a aparência de despudor e liberdade sexual, o mercado e a mídia reproduzem clichês de gênero, indicando como, quando e onde vivenciar uma sexualidade plena e saudável, de forma a concordar com estereótipos que propiciarão um estado de bem-estar e satisfação sexual padronizada (Foucault, /2010). Desse modo, a sexualidade perpetua-se como uma dimensão das relações de poder entre jovens e velhos, pais e filhos, educadores e alunos (Nunes; Silva, 2000; Vianna, 2012).

\section{Menina veste rosa, menino veste azul: a construção dos preconceitos sexistas na infância}

A adoção de papéis sexuais relacionados à concepção de família, às relações de parentesco $e$ às funções paterna e materna foram menos pesquisadas em seus aspectos sociocognitivos, prevalecendo as análises sociológicas (Parisotto et al., 2003; Delval, 2007). Entretanto, a psicologia do desenvolvimento tem contribuído com alguns estudos acerca da constituição das identidades de gênero e das diferenças sexuais. A partir de entramados conceituais de diferentes perspectivas teóricas, a construção dos preconceitos de gênero foi explicada levando em consideração a matriz de um ambiente sociocultural permeado por representações históricas acerca da sexualidade e sua diversidade (Le Maner, 1997; Parisotto et al., 2003). Desde o nascimento, esse processo psicogenético toma as improntas das atitudes comunicativas e afetivas desiguais dos adultos primários (familiares ou professores) conforme sejam direcionadas aos meninos ou às meninas (Moreno, 1999; Reis; Maia, 2009; Madureira; Branco, 2015).

Nesse sentido, as escolhas infantis de jogos e brinquedos também são propiciadas pelas experiências lúdicas diferenciais oferecidas pelos adultos (intencionalmente ou não) e que, na maioria das vezes, respondem a estereótipos de gênero (Le Maner, 1997; Brougère, 1999; Reis; Maia, 2009). Além disso, o público infantil continua sendo o destinatário de clichês fomentados pela indústria dos brinquedos que fortalece os lugares comuns do sexismo com a clássica divisão de brinquedos para meninas e para meninos. Os primeiros continuam relacionados a temáticas domésticas e de cuidados maternos (Le Maner, 1997; Moreno, 1999). O império rosa e banal de Barbie e outras bonecas similares permanece sendo um fenômeno crescente em vendas, promovendo o culto à vaidade, à riqueza e ao corpo perfeito branco, loiro, magro e ocidental (Cechin; Silva, 2012). No caso dos brinquedos "para meninos", proliferam carrinhos, armas e bonecos lutadores que evocam aparatos militares de guerra, fomentando o estereótipo da agressividade (Brougère, 1999; Figueiró, 2009).

Diferentemente, o campo da literatura infantil vem protagonizando um papel transgressor em torno da desconstrução desses estereótipos sexistas. Nos últimos anos, tem surgido uma vasta produção internacional que aborda essa temática em histórias para crianças e adolescentes. Eles apresentam princesas independentes que não querem se casar e preferem atividades historicamente destinadas aos homens, assim como príncipes que gostam de cozinhar e não se mostram sempre fortes e valentes. A crescente presença de famílias homoparentais nos contos também interroga esses papéis sexuais clássicos (Silveira; Kaercher, 2013).

Em síntese, pode-se afirmar que, enquanto os preconceitos sexuais estão sendo foco dos estudos acadêmicos desde um prisma social e cultural, observa-se pouca articulação dessa abordagem com a perspectiva psicogenética da sua construção. A complexidade da sexualidade como campo epistêmico na infância (origem dos bebês, diferença anatômica, de gênero, etc.) exige uma análise não dicotômica desse objeto de assimilação, considerando tanto sua dimensão biológica (físico-anatômica) como a sociocultural (Delval, 2007).

Desde a ótica piagetiana, referência clássica da construção infantil do conhecimento, esse processo envolve uma prolongada e progressiva estruturação cognitiva, em um decurso de diferenciação e integração (Turiel, 2008). Nos seus primórdios, a criança entende o mundo (físico e 
social) em termos de "crenças", e seu pensamento orienta-se a partir de atitudes mentais animistas, artificialistas e mágicas (Piaget, 2005; 1975).

Entretanto, as crenças vão além do pensamento infantil, podendo subsistir nos adultos que acompanham o desenvolvimento das crianças, o que enfatiza o papel do contexto sociocultural na qualidade de sua construção. Por sua vez, as crenças subjetivas são permeadas pelas posições, historicamente diversas, dos grupos culturais de pertencimento que interpretam as práticas sexuais e as identidades de gênero. Por exemplo, as explicações preconceituosas de origem religiosa ou patológica da homossexualidade ilustram, respetivamente, a desumanização e a biologização da sexualidade com base numa moral heterônoma de obediência (Piaget, 1994). Essa moral, característica das crianças do período pré-operatório, forja preconceitos transmitidos e sustentados nos vínculos interpessoais, na mídia ou na linguagem (por exemplo, a utilização da palavra "viado" ou "gay" como insultos).

Na década de 1960, uma pesquisa realizada nos EUA baseada nessa perspectiva piagetiana (Kohlberg, 1966) analisou os aspectos intelectuais da identidade sexuada e evidenciou que esta se desenvolve por estágios psicogenéticos. O termo constância de gênero, escolhido pelo autor ${ }^{1}$, referese ao conhecimento que a criança manifesta acerca da estabilidade da sua condição de menino ou menina ao longo da vida (Le Maner, 1997). A pesquisa, realizada com crianças de 4 a 8 anos, corroborou que as menores de 6 ainda não têm segurança na identificação dessa constância, $e$ mostrou que meninos de 4 anos podem afirmar que quando crescerem serão mães.

$\mathrm{O}$ autor ampliou a pergunta para casos gerais, questionando se uma menina poderia se transformar num menino se ela o desejasse, se brincasse com carrinhos ou se vestisse roupas de meninos e cortasse seu cabelo. Logo, identificou que, na faixa dos 4 anos, a maioria responde que sim, é possível, mas a partir dos 6 já manifestam indícios de "constância de gênero", admitindo que o sexo é estável (Kohlberg, 1966).

Tendo em vista esses achados, Kohlberg (1966) defendeu então a tese de que, para as crianças novas, a diferença genital não seria um critério básico da classificação sexual, sendo o gênero masculino/feminino uma espécie de etiqueta que varia como a roupa. Assim, antes dos 6 anos a criança define o ser homem ou mulher não pela diferença genital/anatômica, mas a partir de elementos contingentes, acessórios e culturais, tais como o comprimento do cabelo, os jogos e brincadeiras, a roupa, etc. Essa distinção etária foi posteriormente corroborada por uma pesquisa realizada na França (Jagstaidt, 1987).

Diante dos resultados desses estudos, realizados nas décadas de 1960 e 1980 no contexto francês e estadunidense, o presente trabalho visou indagar se, quase 50 anos depois, algumas dessas tendências poderiam ser identificadas nas representações de crianças brasileiras do contexto urbano. É importante frisar que, considerando as diferenças entre os contextos anglo-saxão dos anos 60, o francês dos anos 80 e o brasileiro atual, não é o intuito deste trabalho realizar um estudo comparativo, apenas tomamos essas pesquisas como referências metodológicas e conceituais por compartilhar o embasamento piagetiano da nossa investigação. Ademais, tendo constatado que na literatura prevalecem as análises das representações de pais e professores, objetivou-se escutar a voz das próprias crianças. Desse modo, foram entrevistadas 80 crianças, na faixa etária de 4 a 9 anos, para mapear $e$ analisar as transformações das suas crenças sobre as diferenças sexuais $e$ as identidades de gênero. Por último, considerando-se a presença atual da mídia no universo infantil (Tisseron, 2013), indagou-se qual era a principal fonte dessas informações.

\section{“Que diferença da mulher o homem tem?” Escutando as crianças}

Para conhecer as representações de crianças pequenas em relação às diferenças sexuais e de gênero foi realizado um estudo de tipo exploratório, transversal e evolutivo ${ }^{2}$. Foram entrevistadas 80

\footnotetext{
1 Embora consideremos que seria mais precisa a nomenclatura "constância de sexo" em lugar de "constância de gênero", utilizamos a tradução do termo exato escolhido pelo autor. Talvez pela data do trabalho (1966) o conceito desconsidera outras possibilidades sexuais e de gênero, tais como cirurgias ou identidades transgênero.

2 Esse método é tradicionalmente utilizado nas pesquisas de embasamento piagetiano, que buscam explorar a progressão genética do conhecimento, ou seja, a dinâmica da sua construção e transformação ao longo do tempo. É exploratório porque não busca chegar a conclusões explicativas causais acabadas acerca de porque um sujeito chega a um tipo de
} 
crianças, 40 correspondentes à faixa etária de 4 a 6 anos e 40 de 7 a 9 anos (37 meninos e 43 meninas). As crianças pertenciam a três instituições de ensino, duas públicas e uma privada da cidade de Campinas (São Paulo). As entrevistas foram realizadas nas dependências das instituições escolares e gravadas em áudio. O nível socioeconômico geral da amostra era de classe média-baixa e o nível geral escolarização das suas famílias era de ensino médio completo.

Para manter o anonimato, os participantes foram identificados com a letra "E" seguida de um número, e, entre parênteses, a letra $\mathrm{F}$ ou $\mathrm{M}$ (feminino ou masculino) e sua idade (ano, meses). A pesquisa foi aprovada pelo Comitê de Ética em Pesquisa com Seres Humanos (CEPH) da Universidade $\mathrm{X}$, conforme parecer número 1.082.789. Previamente à realização das entrevistas, os adultos responsáveis pelas crianças assinaram um Termo de Consentimento Livre e Esclarecido.

\section{Os bastidores das entrevistas}

Entrevistar crianças pequenas é sempre um desafio, e mais ainda quando a temática envolve sexualidade e gênero no contexto da escola. As entrevistas foram individuais e semiestruturadas constituídas por perguntas básicas de um roteiro geral: [Qual é a diferença entre meninos e meninas? Se um menino quer virar menina, pode? Como? (Caso respondesse "não"): E se brinca de bonecas, deixa o cabelo longo e usa vestido? Se uma menina quer virar menino, pode? Como? (Caso respondesse "não"): E se brinca de carrinhos, corta o cabelo e usa sempre calça?]

Para indagar as fontes de informação, logo após obter as respostas, perguntou-se: [Como é que você sabe disso?]. Com o intuito de criar um clima lúdico e de segurança, utilizou-se, como recurso provocador da fala, pranchas ilustradas com imagens de bebês e personagens infantis. Durante as entrevistas foram feitas perguntas complementares, orientadas pelas respostas das crianças, quando era necessário esclarecer explicações confusas, ambíguas ou para fazer contra sugestões, conforme a indicação do método clínico piagetiano (Piaget, 2005).

Os procedimentos para a análise de dados consistiram, primeiramente, em uma análise qualitativa para estabelecer as grandes tendências e tipos de explicações gerais conforme a escolha de elementos anatômicos e/ou culturais para explicar as diferenças sexuais. Com base na indagação das possibilidades de mudança do "ser menino" e do "ser menina", inferiu-se a distinção infantil entre sexo e gênero. A técnica escolhida centrou-se na análise de conteúdo. Conforme seus lineamentos básicos (Castro; Abs; Sarriera, 2011), foi realizada a leitura exaustiva e minuciosa do material. A codificação do conteúdo focalizou a observação dos principais descritores escolhidos pelos participantes para as diferenças sexuais (termos como: pênis, peito, periquita, etc.) e de gênero (cabelo, brinquedos, roupa, etc). Com base nessa análise, postularam-se três categorias de respostas, tanto para as diferenças sexuais como para os informantes.

Posteriormente, foi realizada uma análise quantitativa (não estatística), sendo as respostas categorizadas e organizadas em tabelas de frequência percentual segundo os grupos etários considerados (4 a 6 e 7 a 9 anos). Em relação às categorias de análise, cabe destacar que, seguindo as postulações de Jagstaidt (1987) e Le Maner (1997), a pesquisa foi circunscrita ao recorte específico do ser menino $x$ ser menina contemplando as diferenças de gênero (propriedades atribuídas pelo contexto sociocultural em relação ao sexo dos sujeitos) e as sexuais anatômicas (manifestações anatômicas e fisiológicas determinadas pelo sexo). Pela idade dos participantes, não houve intuito de abrir as análises a situações de cirurgias para mudança de sexo, os transgêneros $e$ a ambiguidade de sexo ao nascer, entre outros tópicos, sem dúvida, interessantes para futuros trabalhos.

\footnotetext{
conhecimento (considerando que sua gênese multicausal e multidimensional é permeada por dimensões sociais e culturais complexas);.é transversal porque realiza um "corte" sincrônico em uma parcela da população que não é necessariamente representativa em termos estatísticos; é.evolutivo porque pesquisa mudanças no conhecimento, seu desenvolvimento e transformação, tomando como parâmetro o corpo conceitual e as coordenadas das tendências do desenvolvimento infantil investigadas por Jean Piaget ao longo da sua obra. Para mais referências metodológicas inseridas nesse arcabouço teórico, ver: Delval (1994, 2007); Piaget (1005, 1994, 1975); Jagstaidt (1987); e Kohlberg (1966).
} 


\section{"Se a menina cortar o cabelo muito curto vira menino": as crenças infantis, entre o gênero e o sexo}

A leitura exaustiva do material permitiu sistematizar três grupos de respostas sobre as diferenças sexuais e de gênero: as mágico-difusas, as estereotipadas e as anatômicas. A seguir, apresenta-se sua definição, exemplos e distribuição frequencial.

Mágico-difusas: As diferenças estão relacionadas com situações ambíguas e/ou confusas, como a ordem de nascimento ou o progenitor que cuida da criança. $\mathrm{O}$ sexo de um bebê pode ser escolhido pela força do desejo dos pais. A criança não se mostra interessada em aprofundar ou argumentar na sua explicação.

E24 (F 6,2) [Qual é a diferença entre meninos e meninas?] $]^{3}$ Só pelo nome. A minha mãe me deu o nome de X e a minha irmã de Y. Ela pediu para Deus que fossem duas meninas, aí Deus deu eu e a minha irmã.

Estereotipadas: As diferenças menino x menina são baseadas em estereótipos de gênero, tais como cabelo, roupa, atividades, etc. Em concordância com essas explicações, estão justificativas não conservadoras, já que o sexo pode mudar conforme haja modificações dos elementos atribuídos ao universo feminino ou masculino.

E17 (F 5) A menina brinca com a Mônica e o menino com Cascão e com Cebolinha. Os meninos usam short, camisa... E42 (M 9) Nascem iguais, mas vai ficando diferente e uns compram roupa de menino porque é menino e outros compram roupa de menina porque é menina. E aí eles se vestem e ficam diferentes. E73 (M 7) Eu me dou conta pela voz, pela roupa, pela calça, pelo cabelo e pela orelha. E62 $(\mathrm{M} 7,6)$ Quando eles nascem o cabelo fica diferente e a voz também. E10 (F 5) A menina usa calcinha e o menino usa cueca. E34 (M 6) Menino brinca com menino e menina brinca com menina. E21 (F 4,10) Menina usa roupa de menina e faz coisa de menina e menino usa roupa de menino e faz coisa de menino.

Acerca da possibilidade de mudança de sexo, e em concordância com as justificativas estereotipadas, várias crianças expressaram a justaposição gênero-sexo em seus argumentos:

E53 (F 8,8) [Se um menino quer virar menina, pode?] Pode. É só se achar menina. A maioria das meninas não gosta de jogar futebol. Se brincar com carrinho não vira menino. Se a menina cortar o cabelo muito curto ela vira menino. [E se o menino usa vestido vira menina?] Se usar vestido sim.

E62 (M 7,6) [Se uma menina quer virar menino, pode?] Eu acho que sim, se usa vestido de homem. [E um menino?] Sim, pode, põe uma peruca e se veste de mulher. [E vai poder ser mãe?] Não sei.

Anatômicas: As diferenças são baseadas na anatomia, nos órgãos genitais ou a partir de caracteres secundários como o peito. São conservadoras, porque, embora abstenham-se dos elementos clássicos de gênero, tais como brinquedos ou cabelo, o sujeito permanece menino ou menina.

E51 (F 8,10) É que a menina tem aquele negócio e o menino tem aquele. [Como se chamam?] (pensa e ri) Periquita e pinto.

E22 (M 4) O xixi! É que nas meninas os ovinhos são para dentro e nos meninos são para fora. (...) Quando faço xixi com a minha irmã eu vejo. [Qual é a diferença?] O ovário! É assim, é a parte do nosso corpo dentro de nós. Os das mulheres são para fora e dos homens são para dentro. [Alguém falou isso para você?] A minha mamãe.

E48 (F 8) A menina consegue ter filhos e o menino não.

E68 (F 7) Tem pipi ou perereca.

\footnotetext{
3 As falas da entrevistadora são colocadas entre colchetes.
} 
E41 (F 8) A gente percebe por causa do cabelo ou da perereca, e o menino tem pintinho $e$ cabelo bem curtinho.

E43 (M 8) Só o peito.

Cabe destacar que, nas respostas deste grupo, verificou-se uma notória vergonha ao nomear os genitais. As palavras "vagina" e "pênis" eram evitadas, recebendo apelidos ou sendo deixadas implícitas por gestos ou risos de pudor. Amplo e diverso foi o vocabulário utilizado pelas crianças de 7 a 9 anos para substituir o termo "pênis": "aquele negocinho", "pirulim", "pintinho", "pipi", "pirulito", "onde faz xixi", "pinto". No caso da vagina: "a parte íntima", "perereca", "o sexo", "periquita". Para se referir aos órgãos genitais, no geral, algumas crianças assinalavam entre as pernas dizendo "aqui". Em resumo, do total de 23 crianças que responderam de acordo com a categoria "anatômicas" para explicar as diferenças sexuais, somente cinco mencionaram a palavra "vagina" e duas a palavra "pênis".

A respeito da mudança de sexo, as respostas deste grupo demostram, predominantemente, a ideia de constância da diferença sexual: as diferenças menino $x$ menina não são deturpadas só pelo aspecto exterior. Há distinção entre a aparência e a anatomia sexual porque, ainda que a roupa $e$ as atividades habituais de gênero possam fazer alguém "parecer" ser do sexo oposto, a situação fica no plano do "fingir" (tal como argumentado pelos entrevistados E63, E68 e E66). Exemplos:

E68 (F 7) Não [pode mudar], mas pode vestir roupa de menino, cortar o cabelo com negócio de menino. Pode fazer igual a menino. Mas não pode mudar.

E79 (F 7) Não, porque ela já tem o sangue de menina.

E56 (F 9) Poder pode... Meu pai diz que ele [o menino] faz uma plástica no peito, e aí, o resto não sei mais.

E59 (F 8) Pode virar gay. A gente chama de gay isso. Meninos que querem virar meninas ou meninas que querem virar meninos.

E63 (M 7,5) [Se uma menina corta o cabelo e brinca de carrinho, vira menino?] Não pode. Porque não dá para trocar. [E um menino?] Não pode também, por causa da mesma coisa. Ainda que pareça menina não muda.

E66 (F 8,4) [Um menino pode virar menina?] Acho que não. Não... Continua sendo menino porque ele não tem como ter vagina. Se ele quiser fingir de menina, até pode.

Para a análise quantitativa, os tipos de respostas foram organizados na Tabela 1, considerando sua frequência absoluta e percentual segundo os grupos etários.

Tabela 1. Frequência absoluta e percentual das respostas sobre diferenças sexuais e de gênero

\begin{tabular}{ccccc}
\hline Grupos etários & Não sei & Difusas & Estereotipadas & Anatômicas \\
\hline 4 a 6 & $13(32 \%)$ & $8(20,0 \%)$ & $11(28 \%)$ & $8(20 \%)$ \\
\hline 7 a 9 & $5(12 \%)$ & $0 \%$ & $12(30 \%)$ & $23(58 \%)$ \\
\hline
\end{tabular}

Fonte: Garbarino (2012).

Os percentuais das crenças estereotipadas de ambos os grupos não expressam uma grande diferença ( $28 \%$ e $30 \%$, respectivamente), mas, em contrapartida, há maior discrepância nos percentuais das respostas anatômicas (20\% para o grupo de 4 a 6 anos e $58 \%$ para o de 7 a 9).

\section{"A minha mãe uma vez ela já me explicou": os informantes sobre sexualidade e gênero}

Acerca das fontes de informação, as respostas elencadas pelas crianças também foram categorizadas em três grupos:

Autorreferenciais: Respostas do estilo egocêntrico-narcisista. A própria criança aparece no centro da cena, aludindo a vivências presentes e passadas e a qualidades pessoais (considera que 
sabe porque é esperta, inteligente, sempre soube, etc.), mas também a anedotas e narrativas da sua história familiar.

E5 (F 4,8) Como sei? É porque eu nasci sabendo.

E1 (F 4,8) É porque eu sou esperta.

E18 (M 6) Como sei? É que eu sou inteligente, você já sabe disso.

E28 (F 6,1) Eu aprendi sozinha.

Familiares: A criança justifica seu conhecimento aludindo a informantes como a mãe, pai, avós, tias, etc. ou a eventos familiares como nascimentos de primos ou irmãos.

E52 (F 8,7) A minha mãe e minha irmã já me falou.

E63 $(M 7,5)$ Eu lembro quando meu irmão nasceu.

E54 (M 9) A minha mãe uma vez ela já me explicou.

Mídia e escola: A criança afirma saber por meio de informantes da mídia, do âmbito escolar ou de outras instituições educativas. A menção à mídia inclui televisão (novelas, repórter), livros, ultrassom, fotos, vídeos ou internet.

E50 (M 8,7) A professora explicou um pouco.

E43 (M 8,1) Porque eu já vi na televisão.

E77 (M 8) A professora da escola disse (...) Já vi em novela (...) Eu vi no repórter.

Para a análise quantitativa, os tipos de respostas foram organizados na Tabela 2, considerando sua frequência absoluta e percentual segundo os grupos etários.

Tabela 2. Frequência absoluta e percentual das respostas sobre fontes de informação

\begin{tabular}{ccccc}
\hline Grupo etário & Não sei & Autorreferenciais & Familiares & Mídia/Escola \\
\hline \multirow{2}{*}{4 a 6} & 8 & 14 & 13 & 5 \\
& $(20 \%)$ & $(35 \%)$ & $(33 \%)$ & $(13 \%)$ \\
\hline \multirow{2}{*}{7 a 9} & 11 & 0 & 22 & 7 \\
& $(28 \%)$ & & $(55 \%)$ & $(18 \%)$ \\
\hline
\end{tabular}

Fonte: Garbarino (2012).

Observa-se que o grupo das crianças de 4 a 6 anos concentra as respostas autorreferenciais, cujo sistema explicativo prevalece estruturado em torno delas mesmas e de sua família. Já os referentes Familiares possuem uma frequência relativa maior entre as crianças mais velhas (55\% contra $33 \%$ ), o que demonstra um pensamento mais socializado, pela ausência de elementos autorreferenciais $(0 \%)$ nas suas argumentações.

A soma percentual das categorias autorreferenciais e familiares do grupo de 4 a 6 anos totaliza 68\%. Em contrapartida, mais de $70 \%$ das crianças de 7 a 9 anos afirma que seus conhecimentos provêm do entorno familiar ou extrafamiliar. Só em uma ocasião houve menção a informantes mistos (mídia + família), evidenciando-se a mediação do adulto: E65 (F 7,6) Porque tem um vídeo que é em espanhol que fica no youtube. [Você assistiu com sua mãe?] Sim. É que a minha mãe é bióloga e ela me conta.

Embora para ambos os grupos a família seja o informante mais mencionado, cabe sublinhar que, das 35 crianças (do total de 80) que mencionam essa fonte de informação, 29 especificam que foi a mãe quem contou, enquanto nenhuma menciona o pai, o que resulta concordante com pesquisas brasileiras (Reis e Maia, 2009). 


\section{Ser menino e ser menina quando "a gente não pode falar"}

As justificativas das crianças em torno das diferenças de "ser menino" e "ser menina" realizam um movimento que seria representativo de uma progressão genética conforme os grupos etários. Na perspectiva piagetiana (2005, 1994) "progressão" indica mudança com base em estruturas mais expansivas e coordenadas (mas não no sentido positivista hierárquico) e o termo "genética" remete à gênese, ou seja, a uma construção que permite identificar tendências e características ilustrativas que costumam se manifestar ao longo do desenvolvimento infantil. Essas tendências apresentam apenas indícios e traços gerais, mas o conhecimento não resulta em "universal e abstrato", sendo sempre matizado, permeado e organizado com base nos valores dos diversos ambientes socioculturais e históricos.

Sendo assim, pode-se assinalar que, ao analisar as respostas das crianças, foi observada a existência de duas posições a respeito da construção do conhecimento sobre a identidade sexual e de gênero: a dos estereótipos de gênero e a que é calcada na anatomia. Entretanto, a partir das nossas considerações analítico-conceituais já referidas no item método, também foi possível inferir que tais posições não se configuram apenas como dicotomia, havendo posições e opiniões intermediarias, que podem ser vistas como representativas de uma progressão genética desse conhecimento que dá prevalência aos estereótipos de gênero ou à anatomia.

Nesse sentido, tal como foi evidenciado nas respostas estereotipadas e não conservadoras, a marca dessa distinção está em fatores externos como o aspecto físico, as atividades realizadas e o uso de brinquedos e acessórios tipicamente adjudicados ao universo feminino ou masculino. Portanto, a menina que brinca de carrinhos estaria em risco de virar menino, e a brincadeira de bonecas estaria restrita às mulheres. Na mesma lógica, o menino que usa vestido ou deixa o cabelo comprido se tornaria menina, para além da sua vontade.

A força do pensamento preconceitual (Piaget, 1975), base das crenças estereotipadas sobre as diferenças de gênero, favorece essa leitura dicotômica do masculino e do feminino que se instala desde a primeira infância. O raciocínio taxativo do que pertence ao mundo "dos meninos" e ao mundo "das meninas" define a identidade sexuada, própria e alheia, com sustento nesses lugares comuns que fortalecem o reducionismo e, paulatinamente, consolidam os preconceitos sexistas. Contudo, são as ofertas do ambiente as que acabam perpetuando essa aparente dicotomia incipiente, já que o desenvolvimento psicogenético toma as improntas das atitudes comunicativas e afetivas desiguais dos adultos primários (familiares ou professores) conforme sejam direcionadas aos meninos ou às meninas (Le Maner, 1997; Moreno, 1999; Brougère, 1999; Reis; Maia, 2009).

Assim, a indistinção entre gênero e anatomia sexual observada nas crianças mais novas revela, em parte, um traço típico desse período do desenvolvimento. Entretanto, essa divergência não corresponde a uma questão meramente etária ou maturacionista. As pesquisas de Kohlberg (1966) e de Jagstaidt (1987) tinham justificado a concepção conservadora das diferenças sexuais como uma evidencia da consolidação da noção de conservação da substância do pensamento operatório concreto (Piaget, 1975). De acordo com Kohlberg (1966), as dificuldades da criança para estabelecer definições estáveis e constantes sobre a identidade sexual são paralelas às dificuldades de compreensão que apresentam a respeito da conservação da quantidade de matéria e das dimensões dos objetos físicos em geral, características do período preconceitual do pensamento (pré-operatório). Ao longo da progressão psicogenética do conhecimento, as identidades de gênero e a constância sexual mudariam conforme as transformações dos modos básicos de organização cognitiva e das concepções de mundo (Kohlberg, 1966).

Ainda que essa conquista cognitiva seja necessária, contudo, não é suficiente para explicar essas discrepâncias, sendo necessário ampliar sua compreensão, salientando o impacto das posições dos adultos significativos e do contexto sociocultural a respeito do tema. Crianças muito novas que receberam informação familiar conseguiram argumentar a respeito das diferenças sob uma perspectiva ampla e flexível, sem apelar aos clichês de gênero (tal como manifestado por E22 M 4). Também em crianças novas, Delval (1994:437) reconheceu a exploração da instabilidade sexuada em contextos lúdicos, a partir de parâmetros anatômico-genitais: "podemos observar meninos que escondem seu pênis até atrás e dizem 'agora sou uma menina' ou meninas pondo-se algum objeto". 
O próprio Piaget (2005) já tinha advertido que a construção do conhecimento sobre sexualidade é bastante influenciada pelas tendências do contexto sociocultural com o qual a criança interage. Em função desse papel fundante dos ambientes sociais, seu ritmo de progressão difere muito daquele dos objetos lógico-matemáticos (Piaget, 2005). Dessa forma, as tendências do conhecimento construído na infância são modeladas dialeticamente pela experiência subjetiva em contextos culturais (que favorecem ou limitam o conhecimento sexual e os preconceitos), e, ao mesmo tempo, pelos modos básicos de organização cognitiva do desenvolvimento.

Admitindo esse duplo prisma e em concordância com Kohlberg (1966) e Jagstaidt (1987), entretanto, os resultados evidenciam algumas tendências na construção do conhecimento sexual que refletem processos típicos do desenvolvimento infantil. No grupo etário de 4 a 6 anos, a conservação da invariante "órgão sexual" (pênis ou vagina) como critério de classificação dos grupos homem $x$ mulher ainda não está consolidada. As diferenças sexuais tornam-se mais bem definidas pelas crianças mais velhas ao entender que não mudam conforme a realização de atividades e a utilização de objetos estereotipados.

Os elementos até aqui destacados tentam enfatizar a importância da dimensão sociocultural na construção do conhecimento sobre sexualidade e gênero. Esse aspecto mostrou-se pouco atendido nas pesquisas referenciadas (Kohlberg, 1966; Jagstaidt, 1987). Da mesma forma, alguns estudos contemporâneos com embasamento na teoria piagetiana tendem a focalizar a construção psicogenética do conhecimento infantil apresentando a criança como um sujeito "epistêmico", presumidamente universal, apolítico e abstrato. Assim, acabam isolando o desenvolvimento cognitivo postulado por Piaget, desestimando o protagonismo da influência cultural. Esse tipo de leitura da obra piagetiana fortalece os frequentes equívocos de sua interpretação, a partir dos quais ela é vista como uma teoria universalista e maturacionista, que deixaria os educadores e o contexto social em um lugar de contemplação passiva, na espera de uma construção espontânea do conhecimento. Como salientado pelo próprio Piaget (2005), a histórica condição de tabu da sexualidade realça o papel capital dos elementos sociais para promover uma interação que, ora abre espaço para a curiosidade infantil e a construção lúdica de hipóteses acerca do tema, ora favorece a cristalização, a rigidez e a repetição dos nós hegemônicos e dos preconceitos do sexismo, da violência de gênero e da heteronormatividade.

Destarte, a diversidade de posições observadas nas respostas das crianças não é somente oriunda da diferença de faixa etária, e vários foram os indicadores da influência do ambiente. $\mathrm{O}$ atravessamento do contexto social, notadamente do modo como os educadores (família e escola) lidam com o tema da sexualidade, expressou-se no conteúdo das falas, mas especialmente nas formas: nos silêncios, nas sutis ou explícitas manifestações de vergonha ou incomodidade, no recurso de gestos para assinalar partes do corpo, ou nas palavras alusivas. Assim, por exemplo, a respeito dos informantes sobre sexualidade, os resultados permitiram inferir um movimento da autorreferência à contemplação de fontes externas, dentre as quais a escola é a menos mencionada. Nas respostas das crianças mais velhas, prevalece a menção a terceiros ou a suportes midiáticos. Não obstante, o informante mais mencionado por ambos os grupos etários ainda é a família, e, no escopo dessa fonte, a protagonista é a mãe (tanto para as meninas como para os meninos), o que evidencia que a figura feminina é a responsável pela educação dos filhos acerca de assuntos que geram pudor ou controversas (Reis; Maia, 2009). Observou-se ademais que esses adultos significativos podem funcionar como "deformantes" do conhecimento quando apelam a modelos religiosos ou botânicos (teoria da semente, dos anjos, etc).

Como explicar a autorreferência prevalente nas crianças mais novas? Acerca dessas respostas, que envolvem não só qualidades pessoais, mas também lembranças autobiográficas, vale lembrar que, na perspectiva piagetiana, a tendência egocêntrica/narcisista intelectual (o "Eu sei") funciona como a única prova possível da qual a lógica infantil se serve durante muito tempo (Piaget, 1975). Dessa forma, no plano do pensamento verbal, as ideias se tornam crenças. Além disso, no período pré-operatório, a criança remete ao plano do provável, confundindo ficção com realidade (Piaget, 2005).

Além disso, a respeito dos informantes significativos, destaca-se a escassa menção à instituição escolar, amplamente superada pela referência à intimidade endogâmica da educação 
familiar (encarnada nas mães). Esses achados remetem à reflexão foucaultiana acerca do aumento fictício da "liberdade sexual" na contemporaneidade (Foucault, 2010). Mesmo no século XXI, falar sobre sexualidade resulta em constrangimento e evidencia uma resistência que não condiz, por um lado, com a suposta supressão dos tabus e, por outro, com a presença, há já mais de duas décadas, do eixo "orientação sexual" no currículo escolar. Ainda que seja isso um avanço, em matéria de oficializar o tema no contexto escolar, vários pesquisadores já realizaram uma leitura crítica do documento curricular, ressaltando a sua abordagem naturalista, com base em uma concepção biológica que deixa de lado a diversidade sexual e os valores socioculturais que permeiam o sexismo, não indo além da mera informação (Altmann, 2001; Vianna, 2012).

Nesse sentido, vale enfatizar a relevância de se considerar a dimensão sociocultural no momento de se analisar a construção infantil do conhecimento sobre sexualidade e gênero. No contexto escolar brasileiro, destaca-se a recente eliminação de "Orientação Sexual" como tema transversal da nova Base Nacional Comum Curricular (BNCC, Brasil, 2019). Além disso, nos escassos trabalhos brasileiros sobre a questão da abordagem da homossexualidade na escola, há o consenso, por exemplo, de que a união homoparental seja ainda uma estrutura rejeitada em seu estatuto de família, o que corresponde com a ausência do tema no contexto escolar (Cadete; Ferreira; Silva, 2012).

Esses eventos mostram-se inquietantes no contexto dos resultados deste estudo se consideramos que somente abordaram a questão das diferenças sexuais e de gênero, sem adentrar no tema da homossexualidade. Ainda nesse recorte, os dados sugerem que a vergonha para falar sobre sexo é forte entre os adultos da escola e da família, instituições das quais as crianças acabam recebendo informações que fortalecem um tipo de conhecimento artificialista e mágico que alimenta preconceitos. Entretanto, se esse fator educacional não é suficiente para explicar o raciocínio mágico no conteúdo das respostas, ele sim se faz presente nas reações de pudor das crianças. $\mathrm{O}$ riso e as demonstrações de incômodo podem constituir manifestações de vergonha pela exposição ao olhar do outro, neste caso do entrevistador. Conforme La Taille (2002), existe uma suscetibilidade humana irredutível ao olhar alheio, fortalecida quando há sentimentos de inferioridade ou baixa autoestima.

Se a vergonha e o medo podem confundir-se (La Taille, 2002), a distinção entre eles é aqui significativa. Embora as entrevistas começassem com o esclarecimento de que as crianças poderiam falar livremente e de que não havia respostas certas ou erradas, o fato de as conversas terem sido realizadas no ambiente da escola pode ter mobilizado um medo de "punição" nos entrevistados, caso eles mencionassem as palavras que são consideradas "ruins". Por exemplo, sobre o nascimento, E41 (F 8,7) explicou: Às vezes pode cortar a barriga, às vezes pode sair de um negócio que a gente não pode falar. Essa observação do contexto punitivo constitui outra distinção em relação às pesquisas referenciadas (Kohlberg, 1966; Jagstaidt, 1987), cujos autores não mencionaram esse tipo de comentários por parte das crianças entrevistadas. Somente na pesquisa de Jagstaidt algumas manifestações de vergonha aparecem, mas acabam sendo explicadas, exclusivamente, com base no desenvolvimento psicossexual da psicanálise, que postula diques de pudor durante o período da latência.

O medo e a vergonha para abordar a sexualidade emergiram também nos contatos iniciais com as escolas, e muitas coordenadoras negaram a possibilidade de realizar as entrevistas, justificando o medo de represálias das famílias. Todavia, dúvidas e inseguranças sutis permaneceram em algumas das professoras, coordenadoras e diretoras das escolas participantes da pesquisa. Em uma dessas escolas, os entrevistados evidenciaram especial pudor e inibição para falar das diferenças sexuais. Entretanto, a diretora tinha nos informado que os alunos dessa instituição mostravam especial interesse pela temática, mas circunscrito ao horário dos intervalos. Durante o recreio brincavam com bonecos de decoração do pátio da escola, fazendo poses que imitavam relações sexuais entre, por exemplo, uma joaninha e um gnomo.

A mencionada instituição não realizava nenhum projeto ou intervenção de educação sexual, portanto, a sexualidade continuava sendo "explorada" nas margens do discurso oficial. Destarte, de maneira clandestina e isolada da mediação dos adultos, a construção da sexualidade é deixada às possibilidades de cada um, dos seus recursos cognitivos e afetivos e da informação propiciada pelo 
entorno familiar ou midiático. Enquanto a escola permanece alheia à sua responsabilidade de pôr em circulação a palavra, de simbolizar gestos e imagens, as crianças constroem seus próprios espaços, e a sexualidade emerge como aquilo que, segundo E41 (F 8,7), "todo mundo fala no recreio".

Por último, a respeito dos elementos sociais e culturais que permeiam a construção do conhecimento infantil sobre sexualidade, cabe ademais mencionar que, em relação à época das pesquisas aqui referenciadas (Kohlberg, 1966; Jagstaidt, 1987), houve notórias mudanças na quantidade e na qualidade das informações acerca do tema, oriundas da sua mediatização na internet, em livros, programas de TV, materiais pedagógicos, etc. Entretanto, embora atualmente as crianças estejam muito mais expostas a diversas fontes de conteúdo sobre o assunto, seria difícil afirmar que elas sejam mais "sabidas". Nesse sentido, Soler (2002:11) afirmou que "com a evolução dos costumes, a televisão e a educação sexual, revela-se hoje às crianças o que eu chamaria de gestualidade do ato sexual". Enquanto a gestualidade já é bem conhecida, seja pela mídia ou pelas aulas de biologia, a dimensão simbólica, afetiva, sócio-histórica e cultural é ainda pouco vinculada à educação sexual. Onde não há palavras, restam as imagens, os gestos, risos, silêncios ou apelidos, que restringem a capacidade da criança de se autorizar a falar abertamente sobre sexualidade.

Se os preconceitos de gênero e a diversidade sexual são temáticas cada vez mais abordadas na mídia, nas ciências sociais e na literatura infantil, a escola é uma instituição que ainda tem muito caminho a percorrer nessa empreitada. O sexismo subjacente às práticas escolares constitui um problema incontornável, que precisa ser identificado e explicitado para, posteriormente, tomar o estatuto de objeto de conhecimento a ser discutido e desconstruído, a partir de projetos interdisciplinares que permitam a livre manifestação de sentimentos, ideias e crenças sobre o assunto.

A progressiva construção do respeito pela diversidade humana envolve a transformação do herdado e instituído a partir da apropriação plástica dos discursos identitários, educativos e sociais. Essa apropriação marca o início de um posicionamento "enunciador" do Eu, que renuncia à certeza originária dos primeiros vínculos e investe a dúvida para procurar novas significações (Aulagnier, 1977). A escola tem um papel fundante nesse processo. Não obstante, embora a orientação sexual tenha sido um eixo transversal do currículo por mais de duas décadas, e considerando sua atual extinção da BNCC, são as crenças e os posicionamentos subjetivos dos atores escolares que prevalecem em suas práticas e acabam (re)produzindo os lugares comuns do sexismo e da heteronormatividade.

\section{O desafio de desconstruir o tabu da educação sexual na escola: algumas considerações finais}

A sexualidade se apresenta como um objeto de conhecimento que envolve, na sua construção, um conflito simultaneamente cognitivo, socioafetivo e cultural. Entender a orientação sexual por fora dos estereótipos dicotômicos homem $x$ mulher exige, por um lado, esquemas cognitivos que permitam estabelecer relações complexas para entender a diversidade humana como um fenômeno social sofisticado. Por outro lado, é um assunto sobre o qual todo ser humano, desde criança, é interpelado a refletir e a se posicionar subjetivamente, seja pela vivência das mudanças de seu próprio corpo, seja pela autoconstrução da sua identidade sexual. Ao mesmo tempo, a sexualidade se configura em um objeto sociocultural $e$ interpessoal, por ser historicamente um domínio deformado, fantasiado ou anulado, no qual convergem discursos paralelos e fraturas entre o campo da ciência, da religião e da moral.

Há ainda poucos estudos que abordam a construção infantil das diferenças sexuais e de gênero na interface dos aspectos sociais e cognitivos do desenvolvimento. Este trabalho pretendeu contribuir para o preenchimento dessa lacuna visando melhor entender as ressonâncias desse processo na gênese e perpetuação do sexismo. Por um lado, a pesquisa mostrou que o preconceito mantém traços do raciocinar infantil: egocentrismo, reducionismo e dicotomia, além da limitação para coordenar simultaneamente diversos elementos e estabelecer relações entre eles. Contudo, ao mesmo tempo, as peculiaridades do pensamento das crianças, evidenciadas nos ricos argumentos 
dos entrevistados, são um campo fecundo para introduzir, desde cedo, a desconstrução dos estereótipos de gênero e da leitura dicotômica da diferença sexual.

Por outro lado, verificou-se que esses temas ainda permanecem tabus no contexto escolar, sendo a família a principal educadora sexual diante da notória baixa presença da escola. A chuva de estímulos midiáticos na atual conjuntura de suposta liberação e abertura da temática sexual não se torna conhecimento "por osmose"; faz-se necessária a mediação dos adultos escolares $e$ familiares. A educação sexual ainda está longe de ser uma co-construção entre crianças e adultos responsáveis, que acompanhem as hipóteses dos pequenos e os auxiliem nesse processo, quando menos oferecendo um lugar aberto de escuta e circulação de ideias. Assim, uma grande quantidade de estímulo e "informação sexual", à qual as crianças são expostas, não condiz necessariamente em matéria de qualidade quando não consegue ir além de imagens e gestos presentes na mídia. Observa-se assim uma carência de mediação simbólica dessas informações. A vergonha e o pudor dos educadores familiares e escolares para colocar palavras e abrir espaços de conversa a partir dessas imagens, acaba fortalecendo a ideia do segredo e do tabu desses conteúdos que, uma vez acessados na mídia são silenciados, porque deles "não se pode falar".

É responsabilidade da escola a elaboração de projetos que abordem precocemente essas questões, desconstruindo a clássica e hegemônica dicotomia do feminino e do masculino. Nesse intuito, emerge a necessidade de novas pesquisas que aprofundem o diálogo da dimensão sociocultural do desenvolvimento infantil para o estudo da construção dos preconceitos sexuais. Assim, será melhor compreendida a articulação entre as tendências específicas do desenvolvimento $e$ os posicionamentos afetivos $e$ intelectuais dos adultos significativos da criança, que fazem a diferença nesse percurso.

A falta de mediação das instituições sociais como simbolizantes da ebulição visual na mídia traz impactos psíquicos no que diz respeito à construção do conhecimento, mas também à reprodução de preconceitos e tabus - tal como evidenciado nas manifestações de vergonha elencadas. Destarte, as características do desenvolvimento infantil oferecem possibilidades e limites para a abordagem das diferenças sexuais e de gênero. Entretanto, elas somente serão ressignificadas e reorganizadas se houver adultos envolvidos, a partir de uma perspectiva ética e de respeito à diversidade sexual, para mediar e auxiliar sua (des)construção.

\section{Referências bibliográficas}

ALTMANN, Helena. Educação sexual em uma escola: da reprodução à prevenção. Cadernos de Pesquisa v.39, n.136, 2009, pp.175-200.

Orientação sexual nos parâmetros curriculares nacionais. Revista Estudos Feministas 9 (2), 2001, pp.575-585.

AULAGNIER, Piera. La violencia de la interpretación. Buenos Aires, Amorrortu, 1977.

BALIEIRO, Fernando de Figueiredo. "Não se meta com meus filhos": a construção do pânico moral da criança sob ameaça. cadernos pagu (53), Campinas, SP, Núcleo de Estudos de Gênero-Pagu/Unicamp, 2018, e185306 [https://dx.doi.org/10.1590/18094449201800530006 - acesso em: 12 Maio 2019].

BROUGÈRE, Gilles. Les expériences ludiques des filles et des garçons. In: LEMEL, Yannick; ROUDET, Bernard (org.). Filles et Garçons Jusqu'a l'adolescence, Paris, L'Harmattan, 1999, pp.199-222.

CADETE, Vandernúbia Gomes; FERREIRA, Sandra Patrícia Ataíde; SILVA, Dayse Bivar. Os sentidos e os significados produzidos pela escola em relação à família homoparental: um estudo de caso. Interação em Psicologia 16 (1), 2012, pp.101-112 [http://dx.doi.org/10.5380/psi.v16i1.13947 - acesso em: 2 mar 2019].

CAMARGO, Ana Maria Faccioli; RIBEIRO, Claudia. Sexualidade(s) e Infância(s). A sexualidade como um tema transversal. São Paulo, Moderna, 1999.

CASTRO, Thiago Gomes de; ABS, Daniel; SARRIERA, Jorge Castellá. Análise de conteúdo em pesquisas de Psicologia. Psicologia: Ciência e Profissão 31(4), 2011, pp.814-825.

CECHIN, Michelle Brugnera Cruz; SILVA, Thaise da. Assim falava Barbie: uma boneca para todos e para ninguém. Fractal: Revista de Psicologia 24(3), Dec. 2012, pp.623-638 [http://dx.doi.org/10.1590/S198402922012000300012 - acesso em: 23 de outubro, 2021]. 
DELVAL, J. Aspectos de la construcción del conocimiento sobre la sociedad. Educar, Curitiba n. 30, 2007, pp.45-64 [http://www2.marilia.unesp.br/revistas/index.php/scheme/article/view/7146 - acesso em: 3 nov 2018].

El desarrollo humano. Madrid, Siglo XXI de España, 1994.

FIGUEIRÓ, Mary Neide Damico. Educação Sexual: como ensinar no espaço da escola. In: FIGUEIRÓ, M.N.D. (org.). Educação sexual: múltiplos temas, compromisso comum. Londrina, UEL, 2009, pp.141172.

FOUCAULT, Michael. Historia da sexualidade, A vontade de saber (V. 1). RJ, Graal, 2010 [1988].

GARBARINO, Mariana Inés. Crenças sobre a origem dos bebês em crianças de 4 a 9 anos: uma abordagem a partir da psicogênese piagetiana e da psicanálise freudiana. Dissertação (Mestrado em Psicologia Escolar e do Desenvolvimento Humano) - USP, São Paulo, 2012.

GUIMARÃES, Isaura. Educação sexual na escola: mito e realidade. Campinas, Mercado de Letras, 1995.

HIRATA, Helena. Nova divisão sexual do trabalho? São Paulo, Boitempo, 2002.

JAGSTAIDT, V. A sexualidade e a criança. São Paulo, Ed. Manole Ltda, 1987.

KOHLBERG, Lawrence. A cognitive developmental analysis of children's sex role concepts and attitudes. In: Maccoby, E. (org.). The development of sex differences. Stanford, Stanford University Press, 1966, pp.82173.

LA-TAILLE, Yves. Vergonha a ferida moral. Petrópolis, Editora Vozes, 2002.

LE MANER, Gaid Idrissi. L’identité sexuée. Paris, Dunod, 1997.

MADUREIRA, Ana Flávia do Amaral; BRANCO, Ângela Uchoa. Gênero, sexualidade e diversidade na escola a partir da perspectiva de professores/as. Temas em Psicologia 23(3), 2015, pp.577-591 [http://dx.doi.org/10.9788/TP2015.3-05 - acesso em: 3 ago 2019].

MOIZES, Julieta Seixas; BUENO, Sonia Maria Villela. Compreensão sobre sexualidade e sexo nas escolas segundo professores do ensino fundamental. Revista da Escola de Enfermagem da USP 44(1), 2010, pp.205-212 [https://dx.doi.org/10.1590/S0080-62342010000100029 - acesso em: 11 ago 2019].

MORENO, Monserrat. Como se ensina a ser menina: o sexismo na escola. São Paulo, Moderna, 1999.

NUNES, Cesar; SILVA, Edna. A educação sexual da criança. Campinas, Autores Associados, 2000.

PARISOTTO, Luciana et alii. Diferenças de gênero no desenvolvimento sexual: integração dos paradigmas biológico, psicanalítico e evolucionista. Revista de Psiquiatria do Rio Grande do Sul 25 (Suppl. 1), 2003, pp.75-87 [https://dx.doi.org/10.1590/S0101-81082003000400009 - acesso em: 11 ago 2019].

PIAGET, Jean. A representação do mundo na criança. São Paulo, Ideias\&Letras, 2005 [1926].

PIAGET, Jean. O Juízo moral na criança. São Paulo, Ed. Summus, 1994 [1932].

PIAGET, Jean. Seis estudios de psicología. Barcelona, Editora Seix Barral, 1975 [1964].

REIS, Kellen Cristina Florentino; MAIA, Ana Cláudia Bortolozzi. Estereótipos sexuais e a educação sexista no discurso de mães. In: VALLE, T. G. M. (org.). Aprendizagem e desenvolvimento humano: avaliações $e$ intervenções. São Paulo, Cultura Acadêmica, 2009, pp.137-154.

SILVEIRA, Rosa Maria Hessel; KAERCHER, Gládis E. da Silva. Dois papais, duas mamães: novas famílias na literatura infantil. Educação \& Realidade 38(4), 2013, pp.1191-1206 [http://dx.doi.org/10.1590/S217562362013000400010 - acesso em: 9 mar 2019].

SOLER, Colette. A hipótese lacaniana. Revista Percurso 29(2), 2002, pp.5-13 [http://revistapercurso.uol.com.br/index.php?apg $=$ artigo_view\&ida $=788 \&$ ori $=$ autor\&letra $=S$ - acesso em: 9 ago 2019].

TISSERON, Serge. L'enfant et les écrans: un avis de l'Académie des Sciences. Le Carnet PSY v. 169, n. 2, 2013, pp.1-1.

TOKARNIA, Mariana. Mais de um terço de alunos LGBT sofreram agressão física na escola, diz pesquisa. Agência Brasil, 22 de novembro de 2016 [http://agenciabrasil.ebc.com.br/educacao- acesso em: 9 nov. 2018]. 
TURIEL, Elliot. The development of children's orientations toward moral, social and personal orders: more than a sequence in development. Human Development 51, 2008, pp.21-39.

VENANCIO, Ana Teresa Acatauassú; BELMONTE, Pilar Rodriguez. O debate legislativo carioca sobre a "mudança da homossexualidade": ciência, política e religião. Sexualidad, Salud y Sociedad (26), Rio de Janeiro, 2017, pp.103-125 [http://dx.doi.org/10.1590/1984-6487.sess.2017.26.06.a - acesso em: 9 ago 2019]. 